\title{
Pilot Intervention Targeting Sugary Drink Intake Associated With Improvements in Adolescent Sleep Duration
}

\author{
Kelsey A. Egan, MD, MSc ${ }^{1}$; Molly E. Waring, $\mathrm{PhD}^{2}$; Monica L. Wang, ScD, MS $3,4,5$
}

\begin{abstract}
Objective: To examine temporal associations between participation in a community-based intervention targeting sugary drink intake and sleep outcomes among children.

Methods: Data are from an ethnically diverse sample of 100 children aged 9-12 years from 2 Massachusetts Boys and Girls Club (BGC) sites who participated in a pilot-site randomized trial (usual BGC programming plus $\mathrm{H}_{2} \mathrm{GO}$ ! intervention vs usual BGC programming). Secondary outcomes of the trial (sleep duration and adequate sleep duration $[\geq 9 \mathrm{~h} / \mathrm{night}]$ were assessed via a self-report survey at baseline, 2 months, and 6 months. Generalized linear and logistic regression models estimated intervention effects associated with outcomes.

Results: The intervention was associated with increased sleep duration ( $\beta=0.74 ; 95 \%$ confidence interval, $0.03-1.45$ ) and higher odds of adequate sleep (odds ratio, 2.47; 95\% confidence interval, 1.06-5.74) at 2 months. Sleep did not differ by treatment condition at 6 months.

Conclusions and Implications: This community-based sugary drink intake intervention may be a potential avenue to improve child sleep outcomes in the short term.

Key Words: sugar-sweetened beverage consumption, sleep, childhood obesity intervention, communitybased (J Nutr Educ Behav. 2022;54:276-281.)
\end{abstract}

Accepted August 29, 2021. Published online December 14, 2021.

\section{INTRODUCTION}

Insufficient sleep among children and adolescents is associated with increased risk for obesity, ${ }^{1-4}$ depression, ${ }^{1,2}$ and poorer cognitive performance and behavior problems. ${ }^{2,5}$ The American Academy of Sleep Medicine recommends that children aged 6-12 years sleep 9 $-12 \mathrm{~h} / \mathrm{d}^{2}$ Data from the 2015 Youth Risk Behavior Survey (YRBS) indicated that more than half $(57.8 \%)$ of middle school students reported short sleep duration on an average school night $(<9$ hours per night for students aged 6-12 years and < 8 hours per night for students aged $\geq$ 13 years). ${ }^{6}$ The prevalence of short sleep duration among middle school students was significantly higher among non-Hispanic Black (61.1\%) and Native Hawaiian/Pacific Islander $(64.2 \%)$ students compared with non-Hispanic White (56.6\%), Hispanic (57.3\%), and Asian (55.5\%)

\footnotetext{
${ }^{1}$ Division of General Pediatrics, Department of Pediatrics, Boston Medical Center, Boston University School of Medicine, Boston, MA

${ }^{2}$ Department of Allied Health Sciences, University of Connecticut, Storrs, CT

${ }^{3}$ Department of Community Health Sciences, Boston University School of Public Health, Boston, MA

${ }^{4}$ Office of Narrative, Boston University Center for Antiracist Research, Boston, MA

${ }^{5}$ Department of Health Policy and Management, Harvard T.H. Chan School of Public Health, Boston, MA

Conflict of Interest Disclosure: The authors have not stated any conflicts of interest.

Address for correspondence: Monica L. Wang, ScD, MS, Department of Community Health Sciences, Boston University School of Public Health, 801 Massachusetts Ave, Boston, MA 02118; E-mail: Mlwang@bu.edu
}

(C) 2021 The Authors. Published by Elsevier Inc. on behalf of Society for Nutrition Education and Behavior. This is an open access article under the CC BY-NC-ND license (http:// creativecommons.org/licenses/by-nc-nd/4.0/)

https://doi.org/10.1016/j.jneb.2021.08.017

students. ${ }^{6}$ Another study of middle school students indicated shorter sleep duration among those from lower socioeconomic status households.

Multiple cross-sectional studies have found an association between consumption of sugar-sweetened beverages (SSBs) and shorter sleep duration in children and adolescents. $^{8-11}$ Most of these studies hypothesize that shorter sleep duration could lead to altered SSB intake but acknowledge that the relationship may also operate in the opposite direction, in which intake of caffeine-containing SSBs could lead to altered sleep patterns. Data examining longitudinal associations between SSB intake and sleep and from intervention studies targeting SSB intake among child populations are lacking. Furthermore, no studies could be identified that examine the extent to which a childhood obesity prevention intervention solely targeting SSB intake may also impact sleep outcomes over time. This study aims to assess the extent to which a community-based behavioral intervention targeting SSB consumption 
impacts secondary outcomes related to sleep among an ethnically diverse sample of early and preadolescent youth. The hypothesis for this analysis was that participation in the SSB intervention would be associated with increased short-term schoolnight sleep duration and higher odds of adequate sleep ( $\geq 9 \mathrm{~h} /$ night) at 2 and 6 months.

\section{METHODS}

\section{Study Design}

This study was a secondary data analysis of data from a randomized pilot trial of a community-based youth empowerment intervention aimed at decreasing SSB consumption among children. ${ }^{12,13}$ Two Boys and Girls Clubs (BGC) afterschool program sites in Massachusetts were pairmatched for the number of children enrolled and racial/ethnic composition. One BGC site was randomly selected to receive the $\mathrm{H}_{2} \mathrm{GO}$ ! intervention in addition to usual BGC programming, and the other served as the comparison site (usual BGC programming). Outcomes and covariates of interest were measured via self-administered survey assessments at baseline, 2 months, and 6 months. All study protocol and procedures were approved by the Boston University Medical Center Institutional Review Board. This trial was registered at ClinicalTrials.gov (NCT0289. 0056).

\section{Study Setting and Participants}

Boys and Girls Clubs provide a multitude of programs for children from predominantly low socioeconomic backgrounds, including afterschool programs for children aged 9 -12 years. Parent-child pairs from the BGC study sites were recruited inperson by BGC and study staff. ${ }^{12,13}$ Inclusion criteria for children included: aged 9-12 years, a current member of the BGC site, and able to understand and communicate in English. Children were excluded if they had a medical condition that limited their ability to change beverage consumption behaviors. Consent for participation in the study was obtained through written consent forms completed by both child participants and a parent/caregiver.

\section{Intervention}

The $\mathrm{H}_{2} \mathrm{GO}$ ! intervention focused on youth empowerment related to SSB consumption and consisted of 121 hour in-person group sessions over 6 weeks. $^{12,13}$ Each of the 12 sessions was led by trained BGC staff members and occurred in the BGC setting. The development of the $H 2 G O$ ! intervention was informed by the Social Cognitive Theory and the Social Ecological Model. ${ }^{12,13}$ Intervention activities consisted of 3 main components: BGC staff-led interactive sessions focused on knowledge, attitudes, and skills related to decreasing SSB intake (eg, label reading and role-play skits); BGC staff-led narrative sessions and youth sharing of narrative materials produced (eg, print narratives to promote water intake and audio narratives to identify SSBs); and youth-led activities (eg, take-home parent-child activities and an open house healthy beverages event). The intervention activities did not specifically focus on sleep hygiene. Additional details on study protocols and procedures have been previously reported. ${ }^{12,13}$

\section{Measures}

Child participants completed selfreport measures administered in-person on the primary outcome (sleep duration) and covariates at baseline, 2 months, and 6 months. Sleep duration was assessed using an item from the 2015 YRBS Middle School Questionnaire ${ }^{14}$ : "On an average school night, how many hours of sleep do you get?" Given differences in sleep duration on school nights vs weekend nights ${ }^{1}$ and to minimize respondent burden, this study focused specifically on school-night sleep duration. Sleep duration was measured and analyzed continuously; adequate sleep ( $\geq 9$ hours per night) was derived from sleep duration and analyzed as a dichotomous variable. Child sociodemographic variables collected included gender, age, and race/ethnicity. Children were asked, "what is your gender?" with response options of male or female. The children's race/ethnicity was selfreported by children from a list including White, Black or African American, Hispanic/Latino, Asian, Native American/Alaskan Native, Native Hawaiian/Pacific Islander, other. Individuals were asked to check all that apply. Parental/caregiver sociodemographic characteristics, assessed using self-report surveys, included parental education (highest level attained) and household income level.

\section{Statistical Analysis}

Participants who had baseline and at least 1 follow-up assessment were included in the analytic sample. Baseline demographics and characteristics of participants were described using means and standard deviations for continuous variables and frequencies and proportions for categorical variables. Descriptive statistics comparing baseline data between treatment conditions used $t$ tests and chi-square tests of homogeneity, as appropriate. Changes in participant school-night sleep duration from baseline to 2 months and baseline to 6 months were estimated using generalized linear mixed regression models, and odds of reporting adequate sleep duration $(\geq$ 9 hours per night) were estimated using logistic regression models. Crude models were used to estimate 2month and 6-month changes in sleep duration and odds of reporting adequate sleep. Adjusted models controlling for covariates that differed by treatment condition at baseline (child gender and race/ethnicity) ${ }^{13}$ and that have been shown in the literature to be associated with sleep age $^{1}$ and socioeconomic status ${ }^{7}$ ) estimated adjusted 2-month and 6month changes in sleep duration and odds of reporting adequate sleep. Measures of socioeconomic status used in this study included parental education level and household income. Analyses were performed using an intent-to-treat approach. A significance level of $\alpha=0.05$ was used for all statistical tests. Data were analyzed using SAS (version 9.3, SAS Institute, Inc, 2011). 
Table 1. Baseline Characteristics of Children in the $\mathrm{H}_{2} \mathrm{GO}$ ! Pilot Study by Treatment Condition (2016-2017)

\begin{tabular}{|c|c|c|c|c|}
\hline Characteristics & Total $(n=100)$ & $\begin{array}{c}\mathrm{H}_{2} \mathrm{GO} \text { ! Intervention } \\
+ \text { Usual BGC Programming } \\
(\mathrm{n}=51)\end{array}$ & $\begin{array}{l}\text { Usual BGC } \\
\text { Programming } \\
(n=49)\end{array}$ & $\boldsymbol{P}^{\mathrm{a}}$ \\
\hline \multicolumn{5}{|l|}{ Gender } \\
\hline Female & $46(46.0)$ & $29(56.9)$ & $17(34.7)$ & 0.03 \\
\hline Age, y & $10.1(1.0)$ & $10.0(1.1)$ & $10.2(1.0)$ & 0.48 \\
\hline Race $^{\mathrm{b}}$ & & & & 0.001 \\
\hline White & $13(13.0)$ & $4(7.8)$ & $9(18.4)$ & \\
\hline Black & $38(38.0)$ & $26(51.0)$ & $12(24.5)$ & \\
\hline Hispanic/Latino & $20(20.0)$ & $12(23.5)$ & $8(16.3)$ & \\
\hline Asian & $11(11.0)$ & $0(0.0)$ & $11(22.4)$ & \\
\hline Multiracial & $12(12.0)$ & $7(13.7)$ & $5(10.2)$ & \\
\hline Other & $5(5.0)$ & $1(2.0)$ & $4(8.1)$ & \\
\hline Household income level & & & & 0.99 \\
\hline$<\$ 30,000$ & $43(49.4)$ & $22(50.0)$ & $21(48.8)$ & \\
\hline$\$ 30,000-\$ 49,999$ & $25(28.7)$ & $13(29.6)$ & $12(27.9)$ & \\
\hline$\geq \$ 50,000$ & $17(19.5)$ & $8(18.2)$ & 9 (20.9) & \\
\hline Parental education level & & & & 0.22 \\
\hline High school degree & $34(39.1)$ & $14(31.8)$ & $20(46.5)$ & \\
\hline Some college & $27(31.0)$ & $15(34.1)$ & $12(27.9)$ & \\
\hline College degree & $23(26.4)$ & $12(27.3)$ & $11(25.6)$ & \\
\hline $\begin{array}{l}\text { Mean school-night sleep } \\
\text { duration, } h\end{array}$ & $8.1(1.7)$ & $8.0(1.8)$ & $8.1(1.6)$ & 0.67 \\
\hline $\begin{array}{l}\text { Reported adequate } \\
\text { school-night sleep } \\
\text { duration, } \geq 9 \text { h/night }\end{array}$ & $46(46.0)$ & $23(45.1)$ & $23(46.9)$ & 0.85 \\
\hline
\end{tabular}

BGC indicates Boys and Girls Clubs.

${ }^{\text {a }} P$ values reflect results of $t$ tests for continuous variables and chi-square tests of homogeneity for categorical variables (significance level of $\alpha=0.05) ;{ }^{b} \mathrm{n}=1$ missing from $\mathrm{H}_{2} \mathrm{GO}$ ! intervention group.

Note: Values are $\mathrm{n}(\%)$ or mean (SD).

\section{RESULTS}

The analytic sample included 100 participants ( $46 \%$ female; $38 \%$ Black, $20 \%$ Hispanic) with a mean age of 10.1 years (SD, 1.0). At baseline, children reported that they slept for an average of 8.1 hours (SD, 1.7) on school nights, and $46 \%$ of children reported adequate sleep duration on school nights ( $\geq 9$ hours per night). Additional characteristics of the sample at baseline are presented in Table 1. Intervention attendance rates among child participants averaged $78.1 \%(\mathrm{SD}, 10.3)$ across the 12 $\mathrm{H}_{2} \mathrm{GO}$ ! intervention sessions, with $90.5 \%$ of child participants and $74.5 \%$ of parent participants attending the final intervention meeting. ${ }^{13}$ The average fidelity score of intervention delivery was $91.0 \% .{ }^{13}$ The percentage of children reporting adequate school-night sleep duration in the $\mathrm{H}_{2} \mathrm{GO}$ ! intervention was higher than that of the usual BGC programming site at 2 months ( $54.9 \%$ vs $40.8 \%$, respectively) and 6 months $(43.1 \%$ vs $38.8 \%$, respectively) (Table 2).

Crude and adjusted models estimating change from baseline in sleep outcomes between $\mathrm{H}_{2} \mathrm{GO}$ ! intervention and usual BGC programming comparison site participants are presented in Table 2. In unadjusted models, 2- or 6-month change in schoolnight sleep duration or odds of adequate sleep duration did not differ by treatment condition. In adjusted models, children at $\mathrm{H}_{2} G O$ ! Intervention sites reported increased sleep duration on a typical school night from baseline to 2 months $(\beta=0.74$ hours; $95 \%$ confidence interval $[\mathrm{CI}]$, 0.03-1.45; 44.4 minutes) compared with children from usual BGC programming comparison sites. There was no difference in change in sleep duration by treatment condition from baseline to 6 months. Children from $\mathrm{H}_{2} \mathrm{GO}$ ! intervention sites reported more than twice the odds of sleeping $\geq 9 \mathrm{~h} /$ night (odds ratio [OR], 2.47; $95 \%$ CI, $1.06-5.74$ ) at 2 months compared with children from usual BGC programming comparison sites. At 6 months, the odds of adequate sleep duration did not differ by treatment condition.

\section{DISCUSSION}

Findings from this study indicated that participation in a communitybased intervention targeting sugary drink intake was associated with increased school-night sleep duration among children at 2 months after adjusting for child demographics, parental education, and household income. However, increases in sleep duration were not maintained through 6 months. Given that the $\mathrm{H}_{2} G O$ ! intervention was previously shown to be associated with reductions in SSB intake at 2 and 6 months, ${ }^{13}$ the finding that children offered the $\mathrm{H}_{2} \mathrm{GO}$ ! 
Table 2. Two- and 6-month Change in Sleep Outcomes Associated with the $\mathrm{H}_{2}$ GO! Intervention Among Children Aged 9-12 Years $(n=100)$

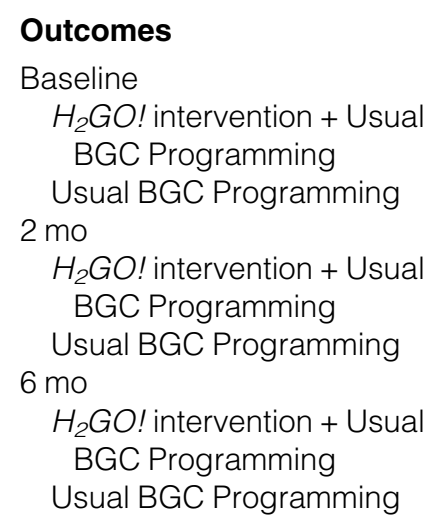

\begin{tabular}{|c|c|c|c|c|c|}
\hline Outcomes & $\begin{array}{l}\text { School-Night } \\
\text { Sleep Duration, } \\
\text { h, Mean (SD) }\end{array}$ & $\begin{array}{c}\text { Change From } \\
\text { Baseline Between } \\
\text { Treatment Conditions, }^{\text {a }} \\
\text { Crude Diff } \\
(95 \% \mathrm{Cl})\end{array}$ & $\boldsymbol{P}$ & $\begin{array}{c}\text { Change From } \\
\text { Baseline Between } \\
\text { Treatment Conditions, }^{\text {a }} \\
\text { Adjusted }^{\mathrm{b}} \\
\text { Diff }(95 \% \mathrm{Cl})\end{array}$ & $\boldsymbol{P}$ \\
\hline \multicolumn{6}{|l|}{ Baseline } \\
\hline $\begin{array}{l}\mathrm{H}_{2} \mathrm{GO} \text { ! intervention + Usual } \\
\text { BGC Programming }\end{array}$ & $8.0(1.8)$ & - & - & - & - \\
\hline Usual BGC Programming & $8.1(1.6)$ & & & & \\
\hline \multicolumn{6}{|l|}{$2 \mathrm{mo}$} \\
\hline $\begin{array}{l}\mathrm{H}_{2} \mathrm{GO} \text { ! intervention + Usual } \\
\text { BGC Programming }\end{array}$ & $8.4(1.5)$ & $0.58(-0.08$ to 1.25$)$ & 0.08 & 0.74 (0.03 to 1.45$)$ & 0.04 \\
\hline Usual BGC Programming & $8.0(1.7)$ & & & & \\
\hline \multicolumn{6}{|l|}{$6 \mathrm{mo}$} \\
\hline $\begin{array}{l}\mathrm{H}_{2} \mathrm{GO} \text { ! intervention + Usual } \\
\text { BGC Programming }\end{array}$ & $8.2(1.4)$ & $0.12(-0.60$ to 0.84$)$ & 0.73 & $0.10(-0.68$ to 0.88$)$ & 0.80 \\
\hline \multirow[t]{2}{*}{ Usual BGC Programming } & $8.2(1.5)$ & & & & \\
\hline & $\begin{array}{c}\text { Adequate } \\
\text { School-Night } \\
\text { Sleep Duration, }\end{array}$ & $\begin{array}{c}\text { Change from } \\
\text { Baseline Between } \\
\text { Treatment Conditions, } \\
\text { Crude OR }\end{array}$ & & $\begin{array}{c}\text { Change from } \\
\text { Baseline Between } \\
\text { Treatment Conditions, } \\
\text { Adjusted }{ }^{\mathrm{b}} \text { OR }\end{array}$ & \\
\hline Outcomes & $\geq 9$ h/night, n (\%) & $(95 \% \mathrm{Cl})$ & $\boldsymbol{P}$ & $(95 \% \mathrm{Cl})$ & $\boldsymbol{P}$ \\
\hline \multicolumn{6}{|l|}{ Baseline } \\
\hline $\begin{array}{l}\mathrm{H}_{2} \mathrm{GO} \text { ! intervention + Usual } \\
\text { BGC Programming }\end{array}$ & $23(45.1)$ & - & - & - & - \\
\hline Usual BGC Programming & $23(46.9)$ & & & & \\
\hline \multicolumn{6}{|l|}{$2 \mathrm{mo}$} \\
\hline $\begin{array}{l}\mathrm{H}_{2} \mathrm{GO} \text { ! intervention + Usual } \\
\text { BGC Programming }\end{array}$ & $28(54.9)$ & $1.90(0.89-4.08)$ & 0.10 & $2.47(1.06-5.74)$ & 0.04 \\
\hline Usual BGC Programming & $20(40.8)$ & & & & \\
\hline \multicolumn{6}{|l|}{$6 \mathrm{mo}$} \\
\hline $\begin{array}{l}\mathrm{H}_{2} \mathrm{GO} \text { ! intervention + Usual } \\
\text { BGC Programming }\end{array}$ & $22(43.1)$ & $1.29(0.53-3.13)$ & 0.57 & $0.81(0.32-2.07)$ & 0.66 \\
\hline Usual BGC Programming & $19(38.8)$ & & & & \\
\hline
\end{tabular}

BGC indicates Boys and Girls Club; $\mathrm{Cl}$, confidence interval; Diff, difference; OR, odds ratio.

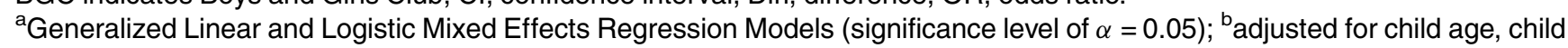
gender, child race/ethnicity, parental education level, and household income. intervention increased their sleep duration by 44 minutes more than children in the comparison site and more than doubled the odds of meeting recommendations for adequate sleep ( $\geq 9 \mathrm{~h} /$ night) at 2 months postintervention suggests that decreasing SSB intake may be a viable intervention strategy to improve short-term sleep duration among early and preadolescents.

The current study's finding supports existing cross-sectional studies that have shown an inverse association between SSB consumption and sleep duration among children of similar age. ${ }^{8-10}$ These studies have primarily focused on the association of shorter sleep duration leading to higher SSB intake (possibly because of an overall increase in consumption of energy-dense food/drinks or because of seeking out caffeine and sugar to increase alertness); however, because these cross-sectional studies are not able to establish directionality, it is plausible that higher SSB consumption leads to shorter sleep duration or that the relationship is bidirectional. The specific mechanisms that may underlie this association are important areas for future investigation.

A potential mechanism for the short-term improvements in sleep duration observed over time in this study is a decrease in caffeine intake, as many SSBs contain caffeine. Caffeine intake by children and adolescents has been linked with decreased sleep duration, ${ }^{15,16}$ difficulty sleeping, $^{17}$ and morning tiredness. ${ }^{17,18}$ The relationship between caffeine intake and sleep may be cyclical, in that the stimulating properties of caffeine may disrupt sleep, leading to daytime sleepiness, which may then 
lead to further increases in caffeine consumption. ${ }^{1}$ Cross-sectional data from fourth- and seventh-grade children indicated that those who slept $<$ 10 hours per day reported more frequent soda (but not juice drink) intake, ${ }^{9}$ which may point to the role of caffeine in the association between SSB consumption and sleep. The significant association between the $\mathrm{H}_{2} \mathrm{GO}$ ! intervention and sleep duration at 2 months relative to the comparison group may not have persisted through 6 months followup because of the intervention more broadly targeting a reduction in SSB consumption, and not specifically SSBs containing caffeine.

At baseline, $46 \%$ of children in the study reported adequate school-night sleep duration of $\geq 9$ hours, slightly higher than the prevalence of $42 \%$ reported by middle school respondents in the 2015 YRBS, who were slightly older than children in this study. ${ }^{6}$ Given that similar racial/ethnic and socioeconomic disparities exist in sleep duration, ${ }^{6,7}$ SSB consumption, $^{19,20}$ and obesity ${ }^{21,22}$ among children, findings from this study suggest that intervening on SSB consumption may be a strategy to improve multiple interrelated outcomes (eg, SSB intake, sleep, and childhood obesity outcomes) among a population at higher risk for these adverse health behaviors and health outcomes.

Strengths of this study include the inclusion of a racial/ethnically diverse population of early and preadolescent children with relatively low socioeconomic status-a disproportionately burdened population with higher rates of insufficient sleep $^{6,7}$ and SSB consumption. ${ }^{19,20}$ Though data on the accuracy of selfreported sleep for children aged 9 -12 years is limited, a recent study comparing the validity of child-reported sleep measures with polysomnography indicated there was a strong agreement for total sleep time (intraclass correlation, $0.722 ; P<$ 0.001) among children aged 9 -17 years. ${ }^{23}$ Given that $2^{24,25}$ out of $4^{24-27}$ studies investigating the association between seasonality and sleep duration in children and adolescents found longer sleep durations in winter months, it is possible that seasonality may have partially contributed to sleep outcomes observed in this study (baseline measures were conducted in the fall, 2-month follow-up measures were conducted in the winter, and 6-month follow-up measures were conducted in the spring). However, the inclusion of a comparison group in this study strengthens the ability to rule out seasonality as a confounder of effects associated with the intervention, as baseline, 2 months, and 6 months measures were collected on both intervention and comparison groups. A limitation of this study is that caffeine intake was not specifically assessed when assessing intake of SSBs; thus, it remains unclear whether caffeine intake was reduced as a result of the intervention or whether changes in caffeine intake explain the findings regarding changes in sleep duration. The findings from these analyses should be considered exploratory because changes in sleep duration were not a prespecified primary outcome in this study. In addition, this pilot study was limited to a sample size of 100 participants at 2 study sites in Massachusetts; results may not be generalizable to other populations. Although individuals from the same site may have more similar (correlated) outcomes than individuals from different sites, we only recruited 2 sites in this pilot trial, and thus we did not adjust for clustering at the site level as the study site does not provide additional information beyond treatment condition. Therefore, the results may be overstated.

\section{IMPLICATIONS FOR RESEARCH AND PRACTICE}

Results from this study suggest that a community-based youth empowerment intervention targeting SSB consumption may lead to short-term improvements in sleep duration among an ethnically diverse sample of youth. These data support the need for future studies of interventions that target SSB intake to further examine the associations between and mechanisms underlying beverage consumption and changes in sleep duration among youth.

\section{ACKNOWLEDGMENTS}

This study was funded by the National Institutes of Health National Institute of Diabetes and Digestive and Kidney Diseases grant no. K01 DK102447 (PI, Monica L. Wang). Dr Kelsey A. Egan was funded under grant no. T32HSO22242 from the Agency for Healthcare Research and Quality, US Department of Health and Human Services. The content of this manuscript is solely the responsibility of the authors and does not necessarily represent the views of the NIH, AHRQ, U.S. Department of Health and Human Services, or any other funders.

The authors would like to thank the staff and study participants at the Boys and Girls Club study sites for their critical input, support, and guidance in informing study procedures and materials.

\section{REFERENCES}

1. Owens J, Adolescent Sleep Working Group, Committee on Adolescence. Insufficient sleep in adolescents and young adults: an update on causes and consequences. Pediatrics. 2014;134: e921-e932.

2. Paruthi S, Brooks LJ, D'Ambrosio C, et al. Consensus statement of the American Academy of Sleep Medicine on the recommended amount of sleep for healthy children: methodology and discussion. J Clin Sleep Med. 2016;12:1549-1561.

3. Poorolajal J, Sahraei F, Mohamdadi Y, Doosti-Irani A, Moradi L. Behavioral factors influencing childhood obesity: a systematic review and meta-analysis. Obes Res Clin Pract. 2020;14:109-118.

4. Patel SR, Hu FB. Short sleep duration and weight gain: a systematic review. Obesity (Silver Spring). 2008;16:643653.

5. Astill RG, Van der Heijden KB, Van Ijzendoorn MH, Van Someren EJ. Sleep, cognition, and behavioral problems in school-age children: a century of research meta-analyzed. Psychol Bull. 2012;138:1109-1138.

6. Wheaton AG, Jones SE, Cooper AC, Croft JB. Short sleep duration among middle school and high school students - United States, 2015. MMWR Morb Mortal Wkly Rep. 2018;67:85-90. 
7. Marco CA, Wolfson AR, Sparling M, Azuaje A. Family socioeconomic status and sleep patterns of young adolescents. Behav Sleep Med. 2011;10:70-80.

8. Chaput JP, Tremblay MS, Katzmarzyk PT, et al. Sleep patterns and sugarsweetened beverage consumption among children from around the world. Public Health Nutr. 2018;21:2385-2393.

9. Franckle RL, Falbe J, Gortmaker S, et al. Insufficient sleep among elementary and middle school students is linked with elevated soda consumption and other unhealthy dietary behaviors. Prev Med. 2015;74:36-41.

10. Kjeldsen JS, Hjorth MF, Andersen R, et al. Short sleep duration and large variability in sleep duration are independently associated with dietary risk factors for obesity in Danish school children. Int J Obes (Lond). 2014;38:32-39.

11. Sampasa-Kanyinga H, Hamilton HA, Chaput JP. Sleep duration and consumption of sugar-sweetened beverages and energy drinks among adolescents. Nutrition. 2018;48:77-81.

12. Wang ML, Lemon SC, Clausen K, Whyte J, Rosal MC. Design and methods for a community-based intervention to reduce sugar-sweetened beverage consumption among youth: H2GO! study. BMC Public Health. 2016;16:1150.

13. Wang ML, Otis M, Rosal MC, Griecci CF, Lemon SC. Reducing sugary drink intake through youth empowerment: results from a pilot-site randomized study. Int $J$ Behav Nutr Phys Act. 2019;16:58

14. Centers for Disease Control and Prevention. 2015 Youth Risk Behavior
Survey middle school questionnaire. https://www.cdc.gov/healthyyouth/ data/yrbs/questionnaires.htm. Accessed February 10, 2021.

15. Pollak CP, Bright D. Caffeine consumption and weekly sleep patterns in US seventh-, eighth-, and ninthgraders. Pediatrics. 2003;111:42-46.

16. Lodato F, Araújo J, Barros H, et al. Caffeine intake reduces sleep duration in adolescents. Nutr Res. 2013;33:726-732.

17. Orbeta RL, Overpeck MD, Ramcharran D, Kogan MD, Ledsky R. High caffeine intake in adolescents: associations with difficulty sleeping and feeling tired in the morning. $J$ Adolesc Health. 2006;38:451-453

18. Watson EJ, Banks S, Coates AM, Kohler MJ. The relationship between caffeine, sleep, and behavior in children. $J$ Clin Sleep Med. 2017;13:533-543.

19. Mendez MA, Miles DR, Poti JM, Sotres-Alvarez D, Popkin BM. Persistent disparities over time in the distribution of sugar-sweetened beverage intake among children in the United States. Am J Clin Nutr. 2019;109:79-89.

20. Bleich SN, Vercammen KA, Koma JW, Li Z. Trends in beverage consumption among children and adults, 2003 -2014. Obesity (Silver Spring). 2018;26:432-441.

21. Ogden CL, Fryar CD, Hales CM, Carroll MD, Aoki Y, Freedman DS. Differences in obesity prevalence by demographics and urbanization in US children and adolescents, 2013-2016. JAMA. 2018;319:2410-2418.

22. Hales CM, Carroll MD, Fryar CD, Ogden CL. Prevalence of Obesity
Among Adults and Youth: United States, 2015-2016. No. 288. US Department of Health and Human Services; 2017.

23. Combs D, Goodwin JL, Quan SF, et al. Mother knows best? Comparing child report and parent report of sleep parameters with polysomnography. J Clin Sleep Med. 2019;15:111-117.

24. Hjorth MF, Chaput JP, Michaelsen K, Astrup A, Tetens I, Sjödin A. Seasonal variation in objectively measured physical activity, sedentary time, cardiorespiratory fitness and sleep duration among 8-11 year-old Danish children: a repeated-measures study. BMC Public Health. 2013;13:808

25. Nixon GM, Thompson JM, Han DY, et al. Short sleep duration in middle childhood: risk factors and consequences. Sleep. 2008;31:71-78.

26. Quante M, Wang R, Weng J, et al. Seasonal and weather variation of sleep and physical activity in 12-14-year-old children. Behav Sleep Med. 2019;17:398410.

27. Hense S, Barba G, Pohlabeln H, et al. Factors that influence weekday sleep duration in European children. Sleep. 2011;34:633-639.

\section{ORCIDs}

Kelsey A. Egan: http://orcid.org/

0000-0002-5802-4502

Molly E. Waring: http://orcid.org/

0000-0002-9884-9824

Monica L. Wang: http://orcid.org/ 0000-0002-7019-5072 